\title{
Proposing Process and Experiment of Drying Roses by Freeze-Drying Method
}

\author{
Nguyen Van Hong ${ }^{1}$, Nguyen Hoai Nam ${ }^{2}$ \\ ${ }^{1,2}$ Faculty of Mechanical Engineering, HCMC University of Technology and Education (HCMUTE), \\ Thu Duc-71307, Ho Chi Minh City, Viet Nam
}

\begin{abstract}
Roses, both fresh and dried, often appear during festive occasions. However, fresh roses do not last long, and dried flowers are marinated with environmentally unfriendly chemicals. This paper proposes the procedure and experiment of drying roses by the freeze-drying method. After drying by the proposed method, the results show that the rose color changes very slightly but still retains its natural, eye-catching, and environmentally friendly appearance.
\end{abstract}

KEYWORDS: Rose, Fresh Rose, Dried Rose, Freeze-Drying Method, Natural Color

\section{INTRODUCTION}

With its beauty, shape, and outstanding fragrance, the rose is one of the most iconic and popular flowers in many countries worldwide. Roses also symbolize the reward of life, soul, heart, love and are often present in many areas of human life, including in art, culture, health, cosmetics, food, and many more. products, etc ${ }^{[1]}$. Dried roses help enjoy this flower longer, keep deep memories, and even help relax when manually drying ${ }^{[2]}$. Five basic ways to dry roses include air drying, desiccant drying, air drying in a vase, drying by microwave, pressing ${ }^{[2]}$. Many drying solutions have been presented in an overview, including dry in the air, dry in the sun, dry by embedded, dry by microwave drying, freezedrying, dry by cryo, press, etc. ${ }^{[3][4]}$. The investigation of the effect of microwave drying on the quality of four Dutch dried roses was conducted ${ }^{[5]}$.

\section{THE FREEZE-DRYING PROCESS}

Figure 1 presents the schematic diagram of the operating principle of freeze-drying equipment in the research.

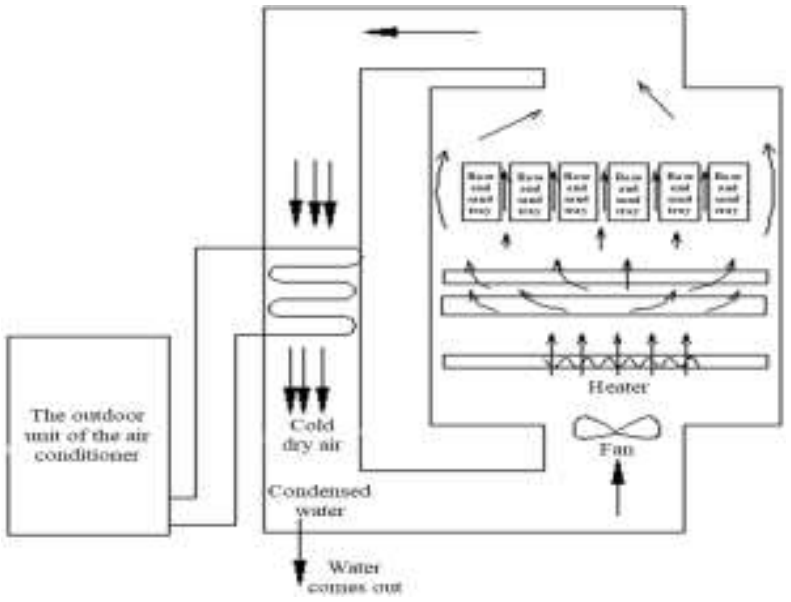

Figure 1. The schematic diagram of the operating principle of freeze-drying equipment
In this study, the freeze-drying process for the roses is described as follows:

- Fresh roses are picked in the morning when the sun makes the flowers almost no water on the surface;

- After harvesting, gently shake or use a fan to blow gently or dry at $100-110^{\circ} \mathrm{C}$ to reach moisture bout 75 $85 \%[6][7][8]$;

- Before freeze-drying, cover with a layer of sand in the tray, put the roses in the tray, cover sand for all the roses in the tray, and put in the dryer equipment;

- Perform freeze-drying at $45-50{ }^{\circ} \mathrm{C}$;

- After freezing-dry, the moisture content of roses is about $8-12 \%{ }^{[6][7][9][10][11][12]}$;

\section{EQUIPMENT AND EXPERIMENT}

The experimentally fabricated freeze-drying equipment is shown in Figure 2.

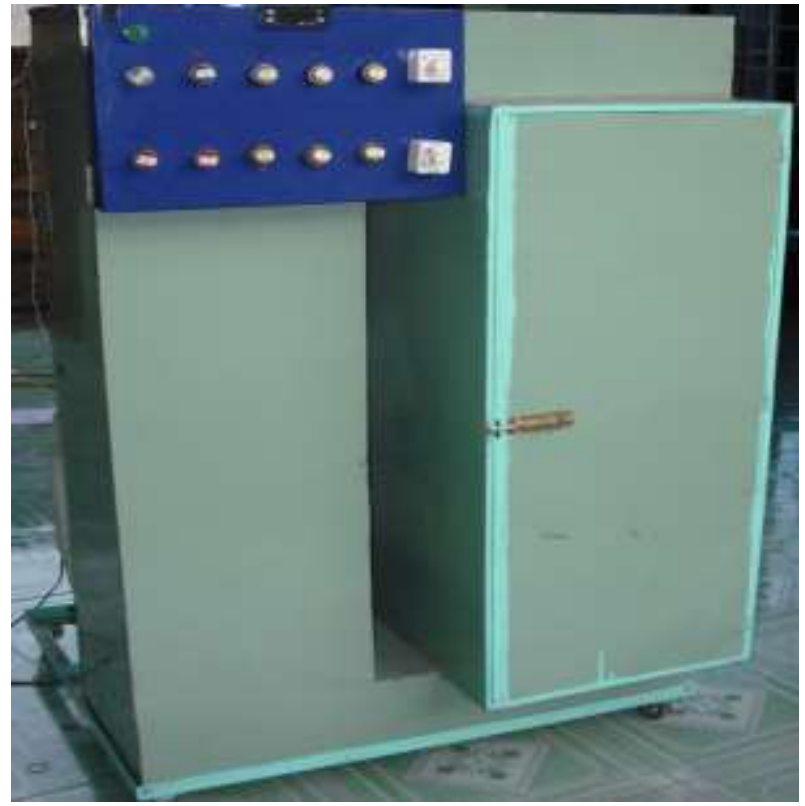




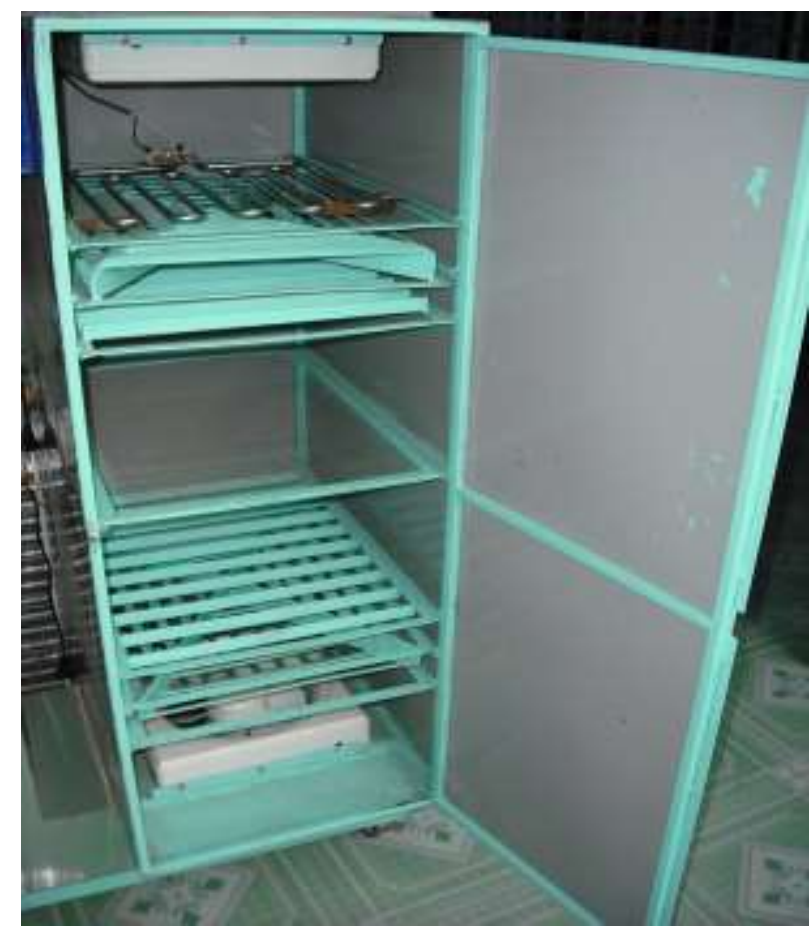

Figure 2. Pictures of the experimentally fabricated freezedrying equipment

\section{IV.RESULTS AND DISCUSSION}

The image of roses after freeze-drying is shown in Figure 3.

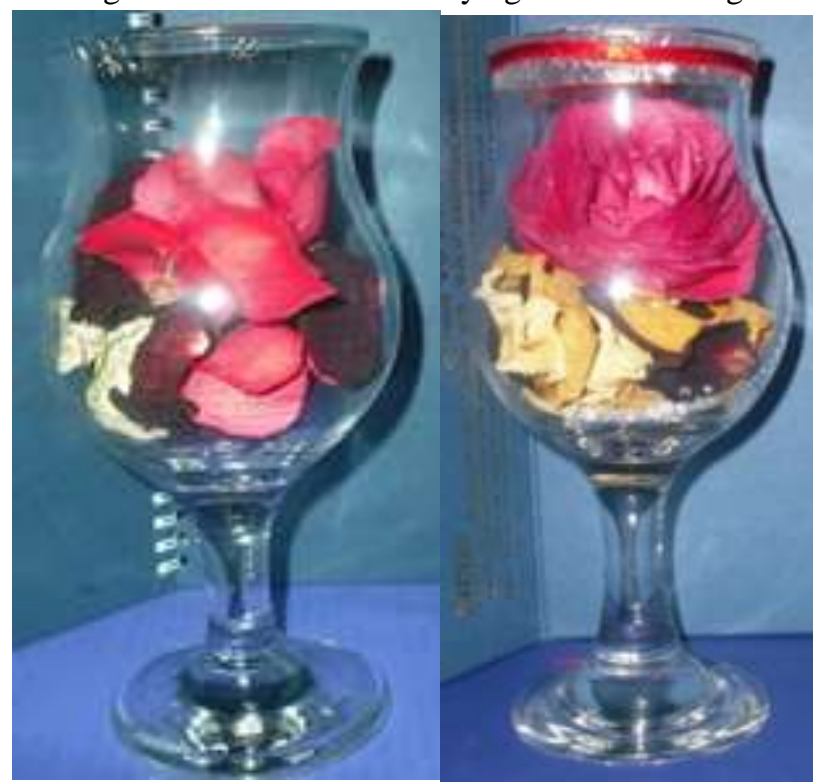

Figure 3. Image of roses after freeze-drying method

Figure 3 shows the color has the slight variation from the original color, but still retains the natural, can meet the user's needs. To overcome that variation, it is necessary to do a lot of research on roses' structure and biochemical properties, which requires a combination of many related fields.

\section{CONCLUSIONS}

The paper presents the drying process for roses and experiments with the freeze-drying method. Before drying with the proposed solution, the research has carried out sand coating for drying objects. After freezing-drying, the roses still retain shape and color almost naturally. At the same time, this drying solution saves a lot of drying time, providing products that can be stored for a long time and are environmentally friendly.

\section{REFERENCES}

1. Information on: https://en.wikipedia.org/wiki/Rose

2. Information on: https://thesmellofroses.com/5best-ways-to-dry-roses-so-they-last-forever/

3. De, L. \& Rai, Wilson \& Thapa, Suman \& Singh, D.R.. 2016. "Drying technologies of commercial flowers-an overview", Impact Factor(JCC): 1.8207, 4, pp. 111-120.

4. Reema Raval, Swati Jayswal and Bharat Maitreya 2020. "Drying Techniques of Selected Flowers: Rosa indica L. And Gerbera Jamesonii L.”, Int J Recent Sci Res., 11(06), pp. 38946-38952.

5. S.A, Safeena \& Patil, Vishwanath. 2014. "Studies on the Effect of Microwave Oven Drying on Flower Quality of Dried Dutch Rose Flowers", National Academy Science Letters, 37, pp. 19-24.

6. Brennan, J. G., 2003. Drying. Theory of air-drying. In: Encyclopedia of food sciences and nutrition, Caballero B, Trugo LC, Finglas PM (eds.), Academic Press, Elsevier Sci Ltd., Oxford, UK, pp. 1913-1917.

7. Polatci, H., 2008. Farklı kurutma yöntemlerinin reyhan (Ocimum basilicum) bitkisinin kuruma süresine ve kalitesine etkisi, Gaziosmanpaşa Üniversitesi Fen Bilimleri Enstitüsü Tarım Makinaları ABD. Yüksek Lisans Tezi, Tokat.

8. Boyar, Serkan \& Bayhan, Ahmet \& Dikmen, Erkan. (2013). Investigation on drying behavior of Isparta rose flowers (Rosa damascena Mill.) under natural shade conditions. Bulgarian Journal of Agricultural Science. 19. 361-374.

9. Pandey PH 2001. "Principles and practices of post harvest technology", Kalyani Publishers, Ludhiana.

10. Singh A 2004. "Study of dehydration of Zinnia", Indian Journal of Plant Physiology. 9(4): 383-387.

11. Singh Alka, Dhaduk BK and Shah RR 2004. "Effect of different temperature and embedding media on flower dehydration of zinnia (Zinnia linearis Benth)", Indian Journal of Horticulture 61(3): 249-252

12. Bs Dilta, Bp Sharma, Hs Bawejaand Bharati Kashyap 2011. "Flower drying techniques - A review", International Journal of Farm Sciences 1(2) : 1-16. 